Published as: Lopez-Fernandez, O., Honrubia-Serrano, M.L., Baguley, T. \& Griffiths, M.D. (2014). Pathological video game playing in Spanish and British adolescents: Towards the Internet Gaming Disorder symptomatology. Computers in Human Behavior, 41, 304-312.

\title{
Pathological video game playing in Spanish and British adolescents: \\ Towards the exploration of Internet Gaming Disorder symptomatology
}

\section{Abstract}

Research into problematic video gaming has increased greatly over the last decade and many screening instruments have been developed to identify such behaviour. This study re-examined the Problematic Videogame Playing [PVP] Scale. The objectives of the study were to (i) examine its psychometric properties in two European countries, (ii) estimate the prevalence of potential pathological gaming among adolescents in both countries, and (iii) assess the classification accuracy of the PVP Scale based on its symptomatology as a way of exploring its relationship with both the behavioural component model of addiction and the proposed Internet Gaming Disorder. The data were collected via a survey administered to 2,356 adolescents aged between 11 and 18 years from Spain $(n=1,132)$ and Great Britain $(n=1,224)$. Results indicated that the reliability of both versions was adequate, and the factorial and construct validity were good. Findings also showed that the prevalence of pathological gamers estimated with a rigorous cut-off point was $\mathbf{7 . 7 \%}$ for Spanish and $14.6 \%$ for British adolescents. The scale showed adequate sensitivity, specificity and classification accuracy in both countries, and was able to differentiate between social and potential pathological 
gamers, and from their addictive symptomatology. The implications of these findings are discussed.

Keywords

Video game playing; Internet gaming disorder; Adolescence; Prevalence; Symptoms; Classification accuracy 


\section{Introduction}

Across the spectrum of cyber-addictions, video game playing (VGP) sometimes referred to as video gaming (VG) - was one of the first potential behavioural activities identified as a 'technological addiction' (Griffiths, 1995; 1996; 1998) including video games played offline via arcade machines, consoles, and handheld devices, and played online via personal computers, laptops, tablets, and mobile phones. As the technologies for playing video games have evolved, so too have the genres and formats. Video gaming is also a very popular leisure activity among adolescents (Kuss \& Griffiths, 2012), considered a habit that has raised concerns because of its potentially addictive nature (e.g., Kuss \& Griffiths, 2012; Prot, McDonald, Anderson, \& Gentile, 2009), and has been referred to as 'video game addiction' (VGA; King, Delfabbro, \& Griffiths, 2013a). This persistent and maladaptive pattern of VGP behaviours has been studied since the early 1980s' first generation of offline video games (Griffiths, 1991; Phillips, Rolls, Rouse, \& Griffiths, 1995) through to online video gaming (OVG; Hussain, Griffiths \& Baguley, 2012). In order to understand this potentially addictive and pathological behaviour, a number of studies have examined the behaviour as clinical entity in populations from both Western and Eastern countries across the world (Anderson et al., 2010; Colwell \& Kato, 2005).

This line of research has been far from systematic (Salguero \& Morán, 2002), and despite the increase of epidemiological studies over the last decade there is still insufficient empirical research to support the notion that VGA could be classed as a psychiatric disorder (King et al., 2013a), although the empirical research is rapidly 
growing (Griffiths, Kuss, \& King, 2012). From the mid-1990s to the present day, the prevalence of VGA among various populations has differed widely. For instance, some papers have estimated that between $6 \%$ and $19 \%$ of individuals are addicted to video games (Tejeiro, Gómez-Vallecillo, Pelegrina, Wallace, \& Emberley, 2012) with others showing even greater variability of between $0.5 \%$ and $46 \%$ (King, Haagsma, Delfabbro, Gradisar, \& Griffiths, 2013b). Some of the main reasons for these wide discrepancies are the different conceptualizations of VGA, the non-standardized scales used to assess VGA, and the use of different methods to estimate the prevalence of VGA. King and colleagues (2013a) noted that the overestimation of VGA prevalence may be due to several factors including: (i) the widespread use of online surveys; (ii) adolescents and young gamers playing more online games (e.g., Massively Multiplayer Online Role Playing Games [MMORPGs]) than middle-aged adults; (iii) cultural differences (e.g., gamers from South East Asia appear to engage in more gaming compared with Western ones and their VGP preferences are different with the first playing more real-time strategy games compared with the second who prefer shooting games); and (iv) high engagement not being sufficiently differentiated from VGA.

As Tejeiro and colleagues (2012) stated, the VGA profile seems to be more heterogeneous and complex. Griffiths (1996) has long written about the biopsychosocial nature of addiction; in relation to VGA, researchers must pay attention to the individual's psychological characteristics (e.g., Haagsma, Caplan, Peters, \& Pieterse, 2013), the sociological context of VGP (e.g., Lemmens, Valkenburg, \& Peter, 2011), and its cultural dimension (e.g., King et al., 2013a). Outside of the individual, to examine the structural characteristics of the video game and other technological 
features (e.g., King, Delfabbro, \& Griffiths, 2011), because the interplay between the individuals, the games they play, and the context in which they play them may help to identify the underlying factors that play a role in the acquisition, development, and maintenance of VGA.

Research into behavioural addictions (e.g., gambling to gaming addiction), suggests that a minority of users experience symptoms traditionally associated with substance-related addictions (Griffiths, 1991). However, the current focus is on understanding the underlying factors of VGP and the possibility that this excessive behaviour leads to a behavioural addiction among adolescents (Topor, Swenson, Liguori, Spirito, Lowenhaupt, \& Hunt, 2011). Traditionally, the most common practice has been to adapt criteria from similar conditions (e.g., pathological gambling) in the Diagnostic and Statistical Manual of Mental Disorders [DSM] (American Psychiatric Association [APA]) to construct diagnostic criteria for technological addictions. Criteria for VGA have mainly been adapted from the DSM criteria for pathological gambling (Griffiths, 1991; Fisher, 1994; Lemmens, Valkenburg, \& Peter, 2009, 2011), but sometimes from the DSM substance dependence criteria (Salguero \& Morán, 2002). In addition to adaptation of DSM criteria, excessive behaviours associated with addictive symptomatology have been also studied using scales developed using the behavioural components model of addiction (Griffiths, 2005) covering its six symptoms (salience, mood modification, tolerance, withdrawal, conflict and relapse). For example, it has been studied in relation to internet addiction (Kuss, Shorter, Rooij, \& Griffiths, 2013), exercise addiction (Terry, Szabo \& Griffiths, 2004), work addiction (Andreassen, 
Griffiths, Hetland \& Pallesen, 2012) and social networking addiction (Andraessen, Tosheim, BrunBerg \& Pallesen, 2012).

At present, the Internet Gaming Disorder [IGD] symptomatology proposed in Section 3 of the latest DSM-5 (APA, 2013) includes nine criteria (i.e., preoccupation, withdrawal, tolerance, unsuccessful attempts to control the OVG behaviour, loss of other activities except OVG, continued OVG despite knowledge of problems, to lie or deceive other people, escape or relieve a dysphoric mood, and to compromise significant relationships). However, it is interesting to note that the DSM-5 uses the terms "internet" and "gaming", and appears to only focus on OVG as a subtype of problematic internet use (Griffiths, King, \& Demetrovics, 2014), although IGD it is still considered as a broader term, namely "Internet Use Disorder" [IUD] (King et al., 2013b; Petry \& O'Brien, 2013); King and colleagues (2013b) state there is still work needed to achieve a terminological consensus between clinicians and researchers, because only three symptoms are consistently measured in the present problematic, pathological or addictive gaming scales (i.e., withdrawal, loss of control and conflict), and only one instrument has shown the capacity to assess the majority of DSM-5 IGD criteria - the Problem Videogame Playing (PVP; Salguero \& Morán, 2002) Scale.

The PVP Scale was the first validated scale to measure "problem video game play", developed to detect video game abusers (Tejeiro et al., 2012). The researchers' first intention was to look for adolescent problems associated with the addictive use of all types of video games (offline and online) and video game systems (consoles and computers). Since its development in 2000 , it has been used in a few studies (e.g., Collins, Freeman, \& Chamarro-Premuzic, 2012; Hart, Johnson, Stamm, Angers, 
Robinson, Lally, \& Fagley, 2009; Kuss, Louws, \& Wiers, 2012; Parker, Taylor, Eastabrook, Schell, \& Wood, 2008), very few have paid attention to the symptomatology measured. However, most studies using PVP have simply compared if differences between groups (Bioulac, Arfi, \& Bouvard, 2008: ADHD children and a controls; Caillon, Bouju, \& GrallBronnec, 2014: adolescents versus adults).

Using this validated scale, the present study has three objectives: (i) to examine its psychometric properties in two European countries, (ii) to estimate the prevalence of pathological gaming among adolescents in Spain and Great Britain, and (iii) to assess the classification accuracy of the PVP Scale based on its addictive symptomatology as a way of exploring its relationship with both the behavioural component model of addiction and the recently proposed IGD.

\section{Method}

\subsection{Participants and procedure}

The study surveyed a convenience sample comprising 2,356 adolescents from two sub-samples in Spain (Barcelona: $n=1,132$ ) and Great Britain (London: $n=1,224$ ). The selection of these countries was twofold: (i) the PVP has only been developed and published in two languages (i.e., Spanish and English), and (ii) according to international organizations, both countries are among those with the highest addiction rates (European Commission, 2006; United Nations Office on Drugs and Crime, 2013). The sample comprised high school students that were selected from several districts in each city, as well as from different school types (state, public and private) to aid 
representativeness. Confidentiality and anonymity was assured to all participants. Additionally, permission to participate in the study was obtained. $92.5 \%$ of students successfully completed all the PVP items in Spain and $77.5 \%$ in Great Britain (Barcelona: $n=1,047$; London: $n=949$ ). The participants were aged between 11 and 18 years (Spain: $M=14.55, S D=1.82$; Great Britain: $M=13.56$; $S D=1.50$ ), and the distribution of ages was segmented following Salguero and Morán's (2002) proposal (the age groups: $11-12,13-15,16-18)$ : in the Spanish were $15.23 \%, 49.8 \%$ and $34.9 \%$; in the British $26.2 \%, 64.7 \%$, and $9.1 \%$ respectively. More than half of the sub-samples were male (Spain: 53.4\%; Great Britain: 67.3\%).

\subsection{Measures}

The paper-and-pencil questionnaire comprised three sections: (a) sociodemographics; (b) video game patterns usage; and (c) the PVP for Spanish and British adolescents using both authors' original versions. The variables examined in the sociodemographic section included: gender, age (in years old), the family unit members (numbers of members living in the same home), the parents' educational level and employment status, participant's place of residence (in or out of city), usual alcohol or tobacco consumption, and other leisure forms of entertainment that did not involve technology. The patterns of gaming use measured were: if they played video games regularly, what type of use they preferred (to play alone, or in company - virtually or physically), if they were the owner of at least one console or a computer with internet to play, at what age they started to regularly play video games (online or offline), their mean time per playing session (in minutes), and their weekly video game frequency 
play (days per week). The PVP is a validated scale originally constructed in Spanish, but published in English (Salguero \& Morán, 2002). It contains nine items rated on a dichotomous scale ( 1 "yes", 0 "no"). The total score ranges between 0 and 9 , with the highest score being the maximum presence of the construct under study in the past year. The scale covers the following eight symptoms (based on substance dependence and pathological gambling disorders proposed in DSM-IV; APA, 1994): preoccupation, tolerance, loss of control, withdrawal, escape, lies and deception, disregard for the physical and psychological consequences, and disruption of family or schooling.

\subsection{Analysis performed}

\subsubsection{Psychometric properties of PVP in Spain and Great Britain}

As the PVP Scale had nine items, and following Nunnally (1978), more than 900 adolescents (10 participants per variable) of each sub-sample (Spain: $n=1047$ : Great Britain: $n=949$ ) were collected and psychometrically analysed. The factor validity of PVP was assessed using Principal Component Analysis (PCA) made on tetrachoric itemscorrelation matrix to each sub-sample, as well as an Exploratory Factor Analyses (EFA) with the Kaiser-Mayer-Olkin index (KMO) and Bartlett's test of sphericity respectively. According to Kaiser's criterion, a factor was obtained (with eigenvalues above 1, factor loadings above 0.3 that explained part of the variance). Item analysis was carried out to observe how the different statements performed in each sub-sample, as well as Cronbach's alpha and McDonald's omega coefficients with their respective confidence intervals (CI) (Dunn, Baguley, \& Brundsen, 2013) to estimate PVP internal consistency in the Spanish and British version. Construct validity was obtained through associations of 
the total PVP score with indicators of two types (VGP time and PVP players' perceptions; Salguero \& Morán, 2002). Moreover, a descriptive analysis of PVP total scores by gender and age was included to update results from Salguero and Morán's (2002) findings. Most of the analyses was carried out using SPSS version 21 . The tetrachoric analyses were carried out using $\mathrm{R}$ packages version 3.0.2 and version 3.3.3.

\subsubsection{Prevalence estimation of VGP users with addictive symptomology}

The prevalence was estimated using two possibilities. First, the cut-off point of 4 (out of 9) to classify "problem players" (following Tejeiro et al., 2012), on the counterpart, users below 4 were considered as "social players". This border was selected following Griffiths' (1991) and Fisher's (1994, 1995) suggestions for the original authors of PVP test, although Tejeiro and colleagues consider that a slight variation of this cut-off point (to 3 or 5 ) did not affect the results from their post-hoc analysis. However, in early studies of VGP, the cut-of point of 4 (out of 9) was for an amusement machine 'addict' (Griffiths, 2001) adapting the DSM-III-R pathological gambling criteria adapted to gaming. Here, a cut-of point of 4 (out of 8 ) indicated the participant was operationally defined as at playing at "addictive" levels (Griffiths \& Dancaster, 1995). Second, in relation to the PVP Scale, recent studies have argued for an increase in the cut-of point. For example, Lemmens et al. (2009) stated that gamers must meet half or more of the diagnostic criteria to be classed as an addict, whereas other researchers have considered it to select a cut-off point of 5 or more to classify users as addicts (Adiele \& Olatokun, 2014; Collins et al., 2012; Turner et al., 2012). Hart et al. (2009) have shown evidence that a cut-off point of 4 or more on the PVP to 
determine addiction is not supported by their findings. This study therefore used this latter option ( 5 or more) to classify potential "pathological players".

\subsubsection{Epidemiological analysis to prove classification accuracy}

The sensitivity, specificity, and overall accuracy of the symptoms measured through the PVP Scale were compared between the pathological players and a random selection of social players with identical sub-samples sizes for each country were extracted by the statistical software used. A procedure similar to previous cyberaddiction studies was used (i.e., Lopez-Fernandez, Honrubia-Serrano, \& Freixa-Blanxart, 2013; Siomos, Dafouli, Braimiotis, Mouzas, \& Angelopoulos, 2008), although these were slightly different because the PVP is a dichotomous response test. Moreover, all the items addressed a single addiction symptom, except items 3 and 6 (that both assessed loss of control). If any player endorsed either one of these it was considered that this symptom of addiction was present within the individual. Additionally, the frequency and percentage of incidence of each symptom was calculated for pathological players.

\subsubsection{PVP in relation with the component model of addiction and the IGD}

Almost all the PVP symptoms can be related to a specific component from the model for behavioural addictions proposed by Griffiths (2005). More specifically, "preoccupation" (Item 1) is a type of cognitive "salience" in Griffiths' model; "tolerance" (Item 2) relates to Griffiths' 'tolerance' component; "loss of control” (item 3) relates to Griffiths' "relapse" component (and the other item that addressed this 
symptom - Item 6 - is a typical gambling symptom known as 'chasing losses', and a reason to remove from the final comparative analysis); "withdrawal" (Item 4) fits Griffiths' 'withdrawal' component; "escape" (Item 5) is "mood modification" in Griffiths' model; and the last three PVP criteria (Items 7, 8 and 9) all relate to Griffiths' component of "conflict" (if any of these three items was endorsed this symptom was present). Similarly, the newly proposed IGD criteria were able to be matched with the PVP items: preoccupation (Item 1), withdrawal (Item 4), tolerance (Item 2), unsuccessful to control (Item 3), loss of activities (item 9), continue despite problems (Item 6), to lie or deceive people (Item 7), escape or relieve (item 5), and to lose personal things (Item 8).

\section{Results}

\subsection{Sample descriptive results}

The initial sample came from families between four and five family members including the adolescent surveyed (Spain: mean [M] was 4.02, standard deviation $[S D]=1.05$; Great Britain: $M=5.19, S D=1.86)$. The majority lived in central Barcelona (95.2\%) or London (71.8\%), with parents employed (Spain: $93.7 \%$ fathers, $83.6 \%$ mothers; Great Britain: $74.2 \%$ and $49.4 \%$ respectively), and who completed secondary school too (Spain: 48\% and 43.7\%; Great Britain: $54.3 \%$ and 55.6\%). A minority of adolescents reported habitual alcohol and/or tobacco consumption (Spain: 23.3\%; 
Great Britain: 12.4\%), and a minority confirmed they used only technology-based leisure entertainment (Spain: 21\%; Great Britain: 30.6\%).

\subsection{Psychometric study of the PVP for Spanish and British adolescents}

\subsubsection{Factor validity}

The tetrachoric items-correlation matrix to each sub-sample demonstrated higher correlations between British PVP items (where the lowest $r_{\text {Items }}$ 3-4 was .3; and higher $r_{\text {Items 1-7 and }} r_{\text {Items 5-7 }}$ was .62) than Spanish PVP items (where the lowest $r_{\text {ltems 4-6 }}$ and $r_{\text {Items } 6-8}$ was .13; and higher $r_{\text {Items } 7-8}$ was .51). The PCA performed on these two matrices showed that one component was sufficient, with a proportion of .26 variance explained for Spain, and .36 for Great Britain. The measures of this factor scored adequately (Spain: correlation of scores with factor .81 , multiple $\mathrm{R}^{2}$ of scores with factor .66 and minimum correlation of possible factor scores .32; Great Britain: $r$ of scores with factor $=.89$, multiple $R^{2}=.79$ and minimum $r$ of possible factor scores $=.58$ ). These results were almost equal to those obtained through the EFA (Spain: KMO=.803; Bartlett's test: $\chi^{2}{ }_{(36)}=757.79 ; \quad p<.001 ;$ Great Britain: $\mathrm{KMO}=.876$; Bartlett's test: $\chi^{2}(36)=1541.11 ; p<.001$ ) that yielded one factor (see Figure 1). The factor "PVP in adolescents" explained 26.7\% of total variance in Spain and 36.7\% in Great Britain.

FIGURE 1

\subsubsection{Item analysis and internal consistency}


Table 1 shows the scores and the analysis of each item per country. When examining the descriptive of participants answering "yes" to the PVP statements, there was variability in their response in each sub-sample. In Spain, Item 6 (loss of control) was the most endorsed (46.9\%) whereas in Great Britain, Item 3 (loss of control) and Item 4 (withdrawal) were the most endorsed (with 39.6 and $40.4 \%$ respectively). In Spain, Items 4 and 8 (disregard for consequences) were the least endorsed (8.9 and 4.3\% respectively) whereas in Great Britain, the least endorsed was Item 8 (although with a higher percentage: $11.4 \%)$. In regards to their factor loading, in both countries the items were above .30, which is important due to the sub-samples sizes (Stevens, 1992). Almost all items (except Item 3 in the Spanish sub-sample) were above 0.45; also squaring the highest factor loadings (Field, 2009) it is estimated that Item 1 (preoccupation) for both countries explained $35.16 \%$ and $48.86 \%$ of total variance of the construct measured. In relation to homogeneity indices, all the items in both subsamples showed expected correlations with the corrected total score (above 0.30). The PVP achieved adequate reliability for a 9-item test (Kline, 1999), with $\alpha=.63[95 \% \mathrm{Cl}$ : $.60, .66]$ for Spain and $\alpha=.78$ [95\% Cl: .76, .79] for Great Britain, and a McDonald's $\Omega=.63[95 \% \mathrm{Cl}: .59, .67]$ for Spain and $\Omega=.78[95 \% \mathrm{Cl}: .75, .80]$ for Great Britain.

TABLE 1

\subsubsection{Construct validity}

\subsubsection{Associations with patterns of usage related with time}


The total M score on the PVP Scale for the Spanish adolescents that completed the whole scale was $1.74(S D=1.70)$, and for the British adolescents was 2.47 ( $S D=2.33)$. Table 2 shows the Spearman correlations between the PVP total score and the patterns of usage related with time. Almost all the variables were significantly positively associated in both countries, with higher PVP scores associated with more days per week adolescents were playing video games (Spain: $r^{2}=.08$; Great Britain: $r^{2}=.07$ ), a greater mean time per session (Spain: $r^{2}=.09$; Great Britain: $r^{2}=.06$ ) and with increasing their maximum time per session (Spain: $r^{2}=.08$; Great Britain: $r^{2}=.05$ ). Significant inverse associations were obtained: the younger the participants started playing the more problematic playing they experienced (Spain: $r^{2}=.03$; Great Britain: $r^{2}=.05$ ), greater frequency of days per week (Spain: $r^{2}=.09$; Great Britain: $r^{2}=.09$ ), more time per playing session (Spain: $r^{2}=.05$; Great Britain: $r^{2}=.04$ ) and longest sessions (Spain: $r^{2}=.05$; Great Britain: $\left.r^{2}=.04\right)$.

TABLE 2

\subsubsection{Associations with PVP perception measures}

Similarly, the analysis of perception of having problematic video gaming revealed significant relationships to PVP Scale score in both countries. The median [Mdn] of the PVP total score was significantly higher for adolescents confirming: 'I think I play video games too much' (Spain: $M_{d n} n_{y e s}=3, M_{n n}=1, U=33947, Z=12.48, p<.001, r=.39$; Great Britain: $\mathrm{Mdn}_{\text {yes }}=4, \mathrm{Mdn}_{\mathrm{no}}=1, U=29510.50, Z=14.23, p<.001, r=.46$ ) 'I think I have some type of problem associated with my video game playing' (Spain: $M d n_{\text {yes }}=4, M n_{n o}=1$, 
$U=9290.50, Z=10.07, p<.001, r=.31$; Great Britain: $M \operatorname{dn}_{\text {yes }}=5, M d n_{n o}=1, U=15207$, $Z=13.02, p<.001, r=.42$ ) and 'My parents are worried because they think I play video games too much' (Spain: $M_{\text {dnes }}=3, M_{n n}=1, U=21017, Z=10.96, p<.001, r=.34$; Great Britain: $\left.\mathrm{Mdn}_{\text {yes }}=5, \mathrm{Mdn}_{\mathrm{no}}=1, U=23567, Z=13.30, p<.001, r=.43\right)$.

\subsubsection{Descriptive of PVP total scores by gender and age}

The descriptive results of the PVP total score of each country in relation to gender and the age groups (See Table 3) show that the proportion of gamers scoring 6 or more (out of 9) in the Spanish adolescents, and 7 or more (out of 9) in the British adolescents was very low (even more so among female players).

TABLE 3

The PVP Mdn score of male players was significantly higher than females (Spain: $U=99586, Z=7.62, p<.001, r=.24$; Great Britain: $U=71632, Z=7.87, p<.001, r=.26)$. As with Salguero and Morán (2002), this could be due because males played significantly more frequently on a daily (Spain: $U=41683.5, Z=7.52, p<.001, r=.28$; Great Britain: $U=43445.5, Z=9.32, p<.001, r=.32$ ) and for significantly longer periods within session (Spain: $M d n_{\text {males }}=90, M d n_{\text {females }}=60 ; U=39899, Z=8.70, p<.001, r=.32$; Great Britain: $\left.M d n_{\text {males }}=90, M_{\text {females }}=60 U=48910.5, Z=8.33, p<.001, r=.28\right)$. No differences were observed in any country in relation to duration of play (Spain: $H_{(2)}=1.87, p=.393$; Great Britain: $\left.H_{(2)}=22.37 p=.795\right)$.

3.3 Estimation of the prevalence of video game "problem" and "pathological" players 
Following Tejeiro and colleagues' (2012) suggested cut-off point of 4 to classify problem players on the PVP scale, the Spanish sub-sample contained 158 participants (15.1\%) and in the British sub-sample contained 286 (30.1\%). These percentages are relatively high, and the present study was more restrictive and rigorous applying a cutoff point of endorsing 5 or more items. Examination of the descriptive results (in Tables 3 and 4 ) showed that in Spain $7.7 \%$ of players $(n=81)$ were classed as potential pathological players, and $14.6 \%$ in Great Britain $(n=179)$. Significant statistical differences were found among each sub-sample. In Spain, the social players (those with less than 5 out of 9) had a mean PVP score of 1.40 (SD=1.26; $M d n=1)$ whereas pathological players had a $M=5.53(S D=1.08 ; M d n=5)(U: Z=15.35, p<.001, r=.47)$. Similarly in Great Britain, social players had a mean PVP score of 1.57 (SD=1.41; $M d n=1)$ while pathological players had a mean PVP score of $6.32(S D=1.36$; $M d n=6)(U$ : $Z=21.17, p<.001, r=.69)$. However, in relation to patterns of video game play, slight significant differences were observed in video game playing between the two types of players, and important significant relationships were detected. For instance, playing daily and for more than two hours were common patterns among potential pathological gamers (see Table 4).

TABLE 4

3.4 Symptoms measured according to the PVP in relation to addiction symptoms

\subsubsection{Incidence and classification function of the PVP symptoms in both countries}


The addiction item with highest incidence was "loss of control" (items 3 and 6; see Table 5), although the second highest addiction symptom was different in each country (i.e., "preoccupation" in Spain and "withdrawal" in Great Britain). However, it appeared that the PVP Scale had adequate capacity to classify types of players as a function of their symptoms, apart from the "disregard consequences" symptom (Item 8) that obtained a low sensitivity in both countries. Statistical differences with effect sizes between medium and large (Cohen, 1992) were observed between both types of players in each country in reference to each single addictive symptom (see Table 6).

TABLES 5 and 6

\subsubsection{The PVP symptoms related with the component model of behavioural} addictions and the IGD

Among the Spanish potential pathological players $(n=81)$, the components in order of frequency from the most prevalent to the lowest were: conflict $(86.4 \%)$, salience (84\%), tolerance (69.1\%), mood modification (67.9\%), relapse (64.2\%), and withdrawal (51.9\%). In the British ( $n=179)$ were: conflict (93.3\%), withdrawal (82.7\%), relapse (77.7\%), tolerance (76\%), salience $(73.2 \%)$ and mood modification (70.9\%). In Spain, only four individuals endorsed all six addiction components, whereas in Great Britain were 44.

In Spain, the pathological player' profile was a male, aged from 13 to 16 from a state school, owner of at least one console (75\%) and a computer with internet (75\%). In Great Britain, similarly, almost all were males (90.7\%), aged from 12 to 17 years old, 
from state schools (63.3\%), owners of at least one console (81.8\%) and a computer with internet (88.6\%). Finally, further analysis showed that if 'salience' and 'mood modification' were not considered compulsory to classify gamer addicts (because could be part of a healthy enthusiasm for video gaming), the prevalence of pathological gaming among Spanish potential pathological gamers would be 12 individuals and 75 among the British counterparts.

TABLE 7

Similarly to Table 3, Table 7 shows the endorsement of each PVP item matched with an IGD criterion per country, gender and age group for pathological players. In Spain, the PVP Item 1 ("preoccupation" IGD symptom) and PVP Item 6 ("continue despite problems" IGD symptom) were endorsed by a majority of the males. In Great Britain, the clearest endorsement among males was PVP Item 4 ("withdrawal" IGD symptom). In both countries, females were much less likely to be pathological players (Spain: 31.5\%; Great Britain: 28.2\%), and an effect of age is observed: the younger the gamers, the more endorsement to these items or symptoms were found. The least endorsed symptom in both countries was PVP item 8 ("loss personal things" IGD symptom).

\section{Discussion}

The purpose of this study was to re-examine the PVP in two countries, due to it being the scale that most closely fitted the proposed IGD criteria in the DSM-5 (King et al., 2013b). The psychometric properties of the Spanish and English versions, from the 
validity analyses, showed its unifactoriality (such as Hart et al., 2009; Turner et al., 2012) through two analysis techniques which achieved very similar results, with an adequate variance explained for a short explorative test (Reckase, 1979), and construct validity through associations with VGP patterns of usage related with time, as well as perception of the own VGP problematic and the significant others perception of the adolescent VGA (King et al., 2013b; Salguero \& Morán, 2002). Reliability measures achieved were fair and identic measured with two coefficients ( $\alpha_{\text {spain }}=.63$ and $\alpha_{\mathrm{GB}}=.78$; $\Omega_{\text {spain }}=.63$ and $\Omega_{\mathrm{GB}}=.78$ ) following Cicchetti (2004), and similar to those obtained by previous studies in Spain ( $\alpha=.69$; Salguero \& Morán (2002), Great Britain ( $\alpha=.75$; Collins et al., 2012), Netherlands ( $\alpha=.78$; Kuss et al., 2012), and Canada ( $\alpha=.79$; Parker et al., 2008). However, other VGA Scales have reported better psychometric properties. For instance, the short Game Addiction scale (GA; Lemmens, et al., 2009) reported a higher internal consistency ( $\alpha=.81$ and .86 ), such as the Problem Video Game Playing Test (PVGT; King, Delbraffo, \& Zajac, 2011: $\alpha=.92$ ) or the Problematic Video Game Use Scale (PVGU; Topor et al., 2011: $\alpha=.83$ ).

The present item analysis of the PVP Scale contributes to the evidence-base that suggests increasing the cut-off point should be increased to a minimum of 5 out of 9 (Adiele \& Olatkun, 2014; Collins et al., 2012; Hart et al., 2009; Lemmens et al., 2009; Turner et al., 2012). In fact, based on the evidence presented here, it could perhaps be argued that the cut-off point be increased at 6 out of 9 criteria to categorize players as having a potential pathological problem. This proposal could be extended to future VGA Scales, based on their addictive criteria measured, and on the basis of empirical and clinical evidence. 
The descriptive findings of the present study showed slight cultural differences, with British gamers tending to play more excessively compared to Spanish gamers. In relation to the addictive symptoms endorsed, both sub-samples converged with "loss of control" being the most endorsed symptom associated with VGA the least endorsed symptom being "disregard for the physical or psychological consequences". However, British adolescents endorsed 'withdrawal' as second most endorsed symptom, while for Spanish adolescents it was the second least endorsed. Comparing the findings of the present study with the few other VGA studies that have explored the addictive symptomatology within a healthy population, there is considerable agreement as to the most endorsed symptoms being 'loss of control/relapse', 'family/school disruption' and 'preoccupation', and the least endorsed symptoms being 'disregard for the consequences' and 'withdrawal' (e.g., Bioulac et al., 2008; Caillion et al. 2014; Gentile, 2009; Turner et al., 2009).

There is a need to periodically update and refine prevalence estimates of adolescent pathological gamers (Gentile et al. (2011) both online and offline (van Rooij, Schoenmakers, Vermulst, van den Eijden, \& van de Mheen (2010)). The present study is the first to make a comparison more than a decade after the first study using the PVP as well as carrying out a cross-cultural comparison simultaneously in different countries with an identical methodology to aid epidemiological research. In this study, the prevalence rates were quite different among countries (Spain: 7.7\%; Great Britain: 14.6\%), although they were inside the common range of PVP Scale prevalence from 2002 (Tejeiro et al., 2012). The classification accuracy of the PVP Scale based on its symptomatology showed notable classification accuracy with high effect sizes in both 
countries (in particular the 'preoccupation' symptom and the 'Consequences' symptom being fair), and was a way of indirectly exploring the PVP Scale with behavioural addiction symptoms. In relation to the components model, both countries showed the 'conflict' component as being highly prevalent (King et al, 2013b) although very few players endorsed all six components. In relation to endorsement of IGD symptoms, a cultural difference was observed. The most highly endorsed items for Spanish gamers were 'preoccupation' (cognitive salience) and 'continue despite problems' (conflict) while in British gamers it was 'withdrawal'. Despite the obvious strengths of the present study (including a large sample size and cross-cultural comparison) there are clearly some limitations; the most obvious of these are the opportunistic and convenience sample used and the self-report method.

\section{Conclusions}

To the authors' knowledge, the present study is the first cross-cultural exploration of IGD symptomatology (i.e., comparing Spanish and British gamers). The study's findings suggest that IGD should be included it in DSM-5's section of "Substance-Related and Addictive Disorders", along with "Gambling Disorder". It is also recommended that researchers in the gaming studies filed should use similar assessment measures to facilitate comparability across demographic groups and to facilitate cross-cultural comparison (Griffiths et al., 2014). Moreover, according to Petry and O'Brien (2013) it is necessary define and describe the features of IGD to be included as a potential new disorder in the DSM-5. However, new scales adapting these 
criteria are needed, and this paper provides empirical evidence for the building of a bridge between the construct of VGA and the newly proposed IGD. 


\section{References}

Adiele, I. \& Olatokun, W. (2014). Prevalence and determinants of Internet addiction among adolescents. Computers in Human Behavior, 31, 100-110.

Anderson, C. A., Shibuya, A., Ihori, N., Swing, E. L., Bushman, B. J., Sakamoto, A., \& ... Saleem, M. (2010). Violent video game effects on aggression, empathy, and prosocial behavior in Eastern and Western countries: A meta-analytic review. Psychological Bulletin, 136(2), 151-173. doi:10.1037/a0018251

Andreassen, C.S., Griffiths, M.D., Hetland, J. \& Pallesen, S. (2012). Development of a Work Addiction Scale. Scandinavian Journal of Psychology, 53, 265-272.

Andraessen, C.S., Tosheim, T., BrunBerg, G.S., \& Pallesen, S. (2012). Development of a Facebook Addiction Scale. Psychological Reports, 110, 501-517.

American Psychiatric Association [APA] (1994). Diagnostic and Statistical Manual of Mental Disorders (4 ${ }^{\text {th }}$ edition). Washington, DC: Author.

American Psychiatric Association [APA] (2013). Diagnostic and Statistical Manual of Mental Disorders (DSM-5). Arlington, VA: Author.

Bioulac, S., Arfi, L., \& Bouvard, M. P. (2008). Attention deficit/hyperactivity disorder and video games: A comparative study of hyperactive and control children. European Psychiatry, 23, 134-141.

Caillon, J., Bouju, G., \& Grall-Bronnec, M. (2014). Jeux vidéo: les motivations et l'intensité de la pratique évoluent-elles avec l'âge ? Comparaison entre une population de joueurs adolescents et adultes. Archives de Pédiatrie, in press. http://dx.doi.org/10.1016/j.arcped.2013.12.018 
Cicchetti, D. V. (1994). Guidelines, criteria, and rules of thumb for evaluating normed and standardised assessment instruments in psychology. Psychological Assessment, 6, 284-290.

Cohen, J. (1992). A power primer. Psychological Bulletin, 112(1), 155-159.

Collins, E., Freeman, J., \& Chamarro-Premuzic, T. (2012). Personality traits associated with problematic and non-problematic massively multiplayer online role playing game use. Personality and Individual Differences, 52, 133-138.

Colwell, J., \& Kato, M. (2005). Video game play in British and Japanese adolescents. Simulation \& Gaming, 36(4), 518-530. doi:10.1177/1046878105279409.

Dunn, T. J., Baguley, T., \& Brundsen, V. (2013). From alpha to omega: A practical solution to the pervasive problem of internal consistency estimation. British Journal of Psychology, 1-14. doi:10.1111/bjop.12046

European Commission (2006). Study of gambling services in the internal market of the European Union. Final Report (Chapter 10: European statistical overview). Laussane: Institut Suisse de Droit Comparé (ISDC). Retrieved 21/09/2014: http://ec.europa.eu/internal market/gambling/links/index en.htm

Field, A. (2005). Discovering Statistics using SPSS ( $2^{\text {nd }}$ edition). Great Britain: Sage.

Fisher, S. E. (1994). Identifying video game addiction in children and adolescents. Addictive Behaviors, 19, 545-553. doi:10.1016/0306-4603(94)90010-8

Fisher, S. E. (1995). The amusement arcade as a social space for adolescents: An empirical study. Journal of Adolescence, 18, 71-86.

Gentile, D. (2009). Pathological video-game use among youth ages 8 to 18. Psychological Science, 20, 594-602. doi:10.1111/j.1467-9280.2009.02340.x 
Gentile, D. A., Choo, H., Liau, A., Sim, T., Li, D., Fung, D., \& Khoo, A. (2011). Pathological video game use among youths: A two-year longitudinal study. Pediatrics, 127, 319-329. doi:10.1542/peds.2010-1353

Griffiths, M. D. (1991). Amusement machine playing in childhood and adolescence: A comparative analysis of video games and fruit machines. Journal of Adolescence, 14(1), 53-73. doi:10.1016/0140-1971(91)90045-S

Griffiths, M. D. (1995). Technological addictions. Clinical Psychology Forum, 76, 14-19.

Griffiths, M. D. (1996). Behavioural addiction: an issue for everybody? Journal of Workplace Learning, 8, 19-25.

Griffiths, M. D. (2008). Internet and video-game addiction. In C. Essau (Ed.), Adolescent Addiction: Epidemiology, Assessment and Treatment (pp. 231-267). San Diego, CA: Elsevier.

Griffiths, M. D. (2005). A "components" model of addiction within a biopsychosocial framework. Journal of Substance Use, 10, 191-197.

Griffiths, M. D., \& Dancaster, I. (1995). The effect of Type A personality on physiological arousal while playing computer games. Addictive Behaviors, 20, 543-548. doi:10.1016/0306-4603(95)00001-S

Griffiths, M. D., Kuss, D. J., King, D. L. (2012). Video game addiction: past, present and future. Curr. Psychiat. Rev., 8, 308-318.

Griffiths, M. D., King, D. L., \& Demetrovics, Z. (2014). DSM-5 internet gaming disorder needs a unified approach to assessment. Neuropsychiatry, 4(1), 1-4. 
Haagsma, M. C., Caplan, S. E., Peters, O., \& Pieterse, M. E. (2013). A cognitivebehavioral model of problematic online gaming in adolescents aged 12-22 years. Computers In Human Behavior, 29(1), 202-209. doi:10.1016/j.chb.2012.08.006

Hart, G. M., Johnson, B., Stamm, B., Angers, N., Robinson, A., Lally, T., \& Fagley, W. H. (2009). Effects of video games on adolescents and adults. CyberPsychology \& Behavior, 12(1), 63-65. doi:10.1089/cpb.2008.0117

Hussain, Z., Griffiths, M. D., \& Baguley, T. (2012). Online gaming addiction: Classification, prediction and associated risk factors. Addiction Research \& Theory, 20(5), 359-371.

King, D. L., Delfabbro, P. H., \& Griffiths, M. D. (2011). The role of structural characteristics in problematic video game play: An empirical study. International Journal Of Mental Health And Addiction, 9(3), 320-333.

King, D. L., Delfabbro, P. H., \& Zajac, I. T. (2011). Preliminary Validation of a New Clinical Tool for Identifying Problem Video Game Playing. International Journal of Mental Health And Addiction, 9, 72-87.

King, D. L., Delfabbro, P. H., \& Griffiths, M. D. (2013a). Chapter 82 - Video Game Addiction. In Miller, P. M., (Ed.). In Principles of Addiction. Comprehensive Addictive Behaviors and Disorders, Volume 1 (pp. 819-825). San Diego, CA: Academic Press.

King, D. L., Haagsma, M. C., Delfabbro, P. H., Gradisar, M., \& Griffiths, M. D. (2013b). Toward a consensus definition of pathological video-gaming: A systematic 
review of psychometric assessment tools. Clinical Psychology Review, 33(3), 331-342. doi:10.1016/j.cpr.2013.01.002

Kline, P. (1999). The handbook of psychological testing (2 ${ }^{\text {nd }}$ edition). Great Britain: Routledge.

Kuss, D. J. \& Griffiths, M.D. (2012). Online gaming addiction in adolescence: A literature review of empirical research. Journal of Behavioral Addictions, 1, 3-22.

Kuss, D. J., Louws, J., \& Wiers, R. W. (2012). Online gaming addiction? Motives predict addictive play behavior in Massively Multiplayer Online Role-Playing Games. Cyberpsychology, Behavior, And Social Networking, 15(9), 480-485. doi:10.1089/cyber.2012.0034

Kuss, D. J., Shorter, G. W., Rooij, A. J., Griffiths, M. D., \& Schoenmakers, T. M. (2013). Assessing internet addiction using the parsimonious internet addiction components model-a preliminary study. International Journal of Mental Health and Addiction. Advance online publication. doi:10.1007/s11469-013$9459-9$

Lemmens, J. S., Valkenburg, P. M., \& Peter, J. (2009). Development and validation of a game addiction scale for adolescents. Media Psychology, 12(1), 77-95. doi:10.1080/15213260802669458

Lemmens, J. S., Valkenburg, P. M., \& Peter, J. (2011). Psychosocial causes and consequences of pathological gaming. Computers In Human Behavior, 27(1), 144-152. doi:10.1016/j.chb.2010.07.015

Lopez-Fernandez, O., Freixa-Blanxart, M., \& Honrubia-Serrano, M.L. (2013). The Problematic Internet Entertainment Use Scale for Adolescents: prevalence of 
problem internet use in Spanish high school students. CyberPsychology, Behavior, and social networking, 16,108-118. doi:10.1089/cyber.2012.0250 Nunnally, M.J. (1978). Psychometric theory. New York, NY: Mc Graw-Hill. Parker, J. A., Taylor, R. N., Eastabrook, J. M., Schell, S. L., \& Wood, L. M. (2008). Problem gambling in adolescence: Relationships with internet misuse, gaming abuse and emotional intelligence. Personality And Individual Differences, 45(2), 174-180. doi:10.1016/j.paid.2008.03.018

Petry, N. M., \& O'Brien, C. P. (2013). Internet gaming disorder and the DSM-5. Addiction, 108(7), 1186-1187.

Phillips, C. A., Rolls, S., Rouse, A., \& Griffiths, M. D. (1995). Home video game playing in schoolchildren: A study of incidence and patterns of play. Journal of Adolescence, 18(6), 687-691. doi:10.1006/jado.1995.1049

Prot, S., McDonald, K. A., Anderson,C. A., \& Gentile, D. A. (2012). Video Games: Good, Bad, or Other? Pediatric Clinics of North America, 59(3), 647-658.

Ricquebourg, M., Bernède-Bauduin, C., Mété, D., Dafreville, C., Stojcic, I., Vauthier, M. Galland, M.-C. (2013). Internet et jeux vidéo chez les étudiants de La Réunion en 2010 : usages, mésusages, perceptions et facteurs associés. Revue d'Épidémiologie et de Santé Publique, 61(1), 503-512.

Reckase, M. (1979). Unifactor latent trait models applied to multifactor tests: Results and implications. Journal of Educational Statistics, 4, 207-230.

Salguero, R. A. T., \& Morán, R. M. B. (2002). Measuring problem video game playing in adolescents. Addiction, 97(12), 1601-1606. doi:10.1046/j.13600443.2002.00218.x 
Siomos, K., Dafouli, E., Braimiotis, D., Mouzas, O., \& Angelopoulos, N. (2008). Internet addiction among Greek adolescent students. CyberPsychology \& Behavior, 11, 653-657. doi:10.1089/cpb.2008.0088

Stevens, J. P. (1992). Applied multivariate statistics for the social sciences ( $2^{\text {nd }}$ edition). Hillsdale, NJ: Erlbaum.

Tejeiro, R. A., Gómez-Vallecillo, J. L., Pelegrina, M., Wallace, A., \& Emberley, E. (2012). Risk factors associated with the abuse of video games in adolescents. Psychology, 3(4), 310-314. doi:10.4236/psych.2012.34044

Terry, A., Szabo, A. \& Griffiths, M.D. (2004). The Exercise Addiction Inventory: A new brief screening tool, Addiction Research and Theory, 12, 489-499.

Topor, D. R., Swenson, L. P., Liguori, G. M., Spirito, A., Lowenhaupt, E. A., \& Hunt, J. I. (2011). Problematic video game use scale: Initial psychometric properties with psychiatrically hospitalized adolescents. Journal of Clinical Psychiatry, 72(12), 1611-1615. doi:10.4088/JCP.11m07040

Turner, N. E., Paglia-Boak, A., Ballon, B., Cheung, J. T. W., Adlaf, E. M., Henderson, J., . . Mann, R. E. (2012). Prevalence of problematic video gaming among Ontario adolescents. International Journal of Mental Health and Addiction, 10(6), 877889. doi:10.1007/s11469-012-9382-5

United Nations Office on Drugs and Crime (2013). World Drug Report 2013. Maps and graphs. Retrieved 21/09/2014: http://www.unodc.org/wdr/en/maps-andgraphs.html

Van Rooij, A. J.; Schoenmakers, T. M., Vermulst, A. A.; Van den Eijden, R. J. J. M., \& Van de Mheen, D. (2010). Online video game addiction: identification of addicted 
adolescent gamers. Addiction, 106, 205-212. doi:10.1111/j.13600443.2010.03104.x 